\title{
Weaning practices and breast-feeding duration in Northern Thailand
}

\author{
BY DOROTHY A. JACKSON ${ }^{1}$, STELLA M. IMONG ${ }^{1}$, \\ LUMDUAN WONGSAWASDII', ADUNG SILPRASERT ${ }^{2}$, \\ SAKDA PREUNGLAMPOO ${ }^{2}$, POSRI LEELAPAT ${ }^{2}$, R. F. DREWETT ${ }^{3}$, \\ KOSIN AMATAYAKUL ${ }^{2}$ AND J. D. BAUM ${ }^{1}$ \\ ${ }^{\mathrm{I}}$ Institute of Child Health, University of Bristol, Bristol BS2 8BJ, ${ }^{2}$ Research Institute for Health \\ Sciences, Chiang Mai University, Thailand, ${ }^{3}$ Department of Psychology, University of Durham
}

(Received 3 October 1990 - Accepted 8 May 1991)

\begin{abstract}
Current infant feeding guidelines recommend exclusive breast-feeding until the infant is about $\mathbf{4}$ months old to reduce the risks of early termination of breast-feeding, undernutrition and infection. In many societies, however, supplementary foods are given well before 4 months of age. The present paper describes weaning practices, factors associated with early supplementation and the effects of supplementation on duration of breast-feeding in a random sample of sixty northern Thai breast-fed infants studied prospectively from birth to 2 years of age. Composition of supplementary foods, energy and protein intake from supplements and changes in the supplementary diet with increasing infant age are also described. Rice-based foods were given from soon after birth; $81 \%$ of the sample had received supplements by 6 weeks of age. Early supplementary feeding was significantly associated with rural residence, large household size, maternal employment in agriculture and maternal age. Girls and infants with lower birth weights tended to be supplemented earlier. Despite early feeding of supplements, breastfeeding was prolonged, with median duration of 12 months. Early introduction of supplements and quantity of supplements consumed in the first 3 months were not associated with duration of breastfeeding. However, mothers who gave infant formula as the first supplementary food stopped breastfeeding slightly earlier, as did younger mothers living in households with more children.
\end{abstract}

Breast-feeding: Supplementary feeding: Weaning

International guidelines on infant feeding practice discourage supplementary feeding before the age of about 4 months due to the hazards of microbial contamination, the potentially inferior nutritional composition of supplementary foods compared with breastmilk, and the possibility that early supplementary feeding can lead to early termination of breast-feeding (Underwood \& Hofvander, 1982). However, in many developing countries exclusive breast-feeding for the first 4 months of life is unusual. Infants are given supplementary foods from an early age and there may be a prolonged period of mixed breast- and supplementary feeding until the infant is weaned completely from the breast (World Health Organization, 1981; Latham et al. 1986; Dimond \& Ashworth, 1987).

Little is known of the factors predisposing to early supplementary feeding in different cultures. The present study describes the pattern of supplementary feeding and the weaning diet of breast-fed infants in a predominantly rural area of northern Thailand; it investigates predictors of early supplementary feeding and examines whether early supplementation is in fact associated with earlier cessation of breast-feeding.

\section{METHODS}

The study forms part of a prospective study of infant health and growth, carried out in an area $25 \mathrm{~km}$ south-west of the northern Thai city of Chiang Mai. The study area (about 


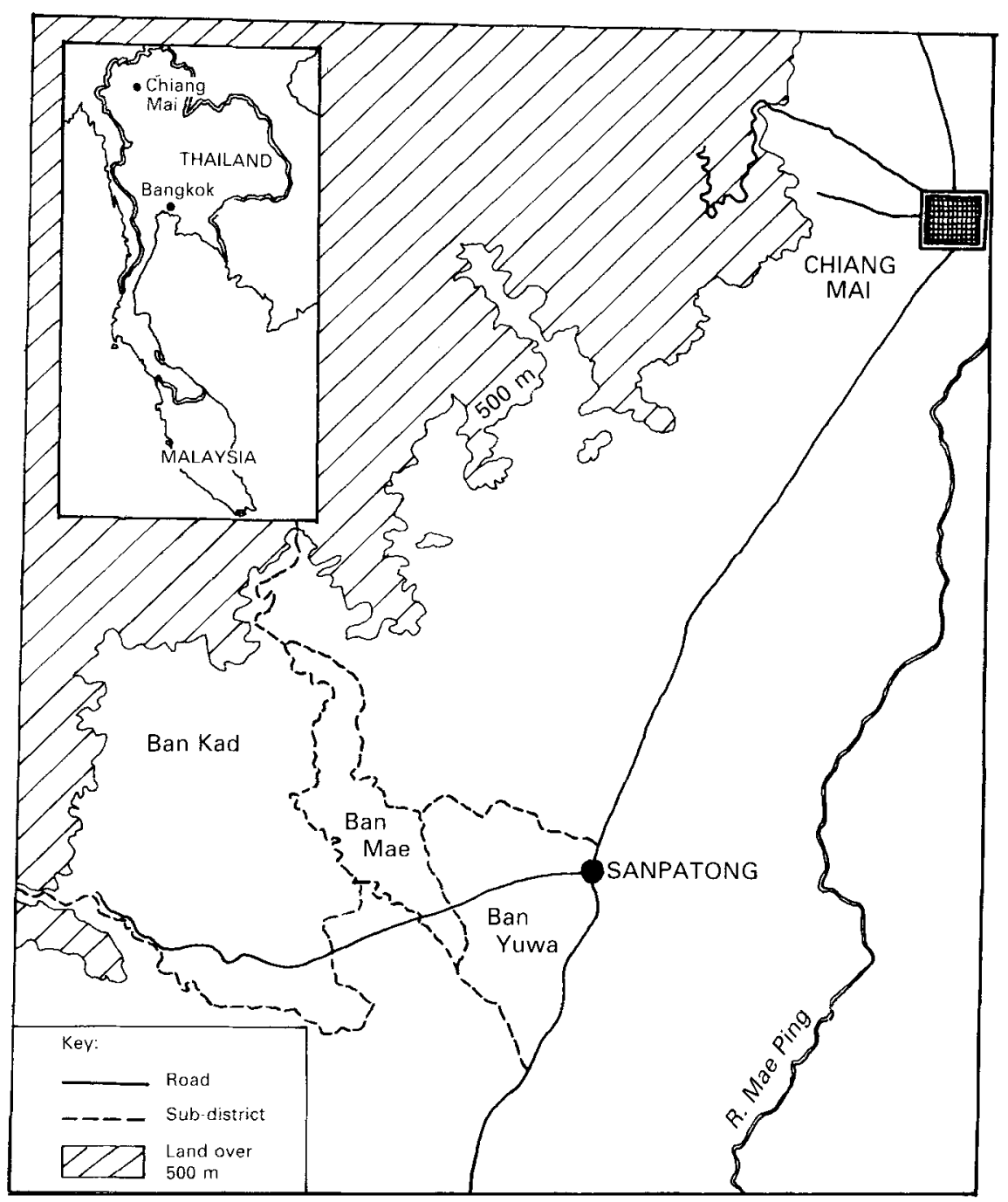

Fig. 1. Map of the study area.

$60 \mathrm{~km}^{2}$ ) comprised three adjacent sub-districts (thirty-six villages). Ban Yuwa was the most affluent sub-district, encompassing the small market town of Sanpatong on the main road to Chiang Mai. Ban Kad was the most rural sub-district, situated in the less fertile uplands encircling the Chiang Mai basin and furthest from the main road. Ban Mae lay between these two sub-districts, and was intermediate in character (Fig. 1).

Sixty-two infants were recruited by systematic random selection (every seventh birth) from the cohort of 449 births occurring between July 1985 and September 1986. The database of births in the study area was compiled from thrice-weekly surveys of hospital and clinic records and thrice-weekly visits to health volunteers who kept notes on all pregnant women and births in their village.

Infants were included in the study if they were: ethnically northern Thai; a singleton birth; had no detectable congenital abnormality, inherited condition or chronic disease; and were resident at home and breast-feeding on the day of recruitment (day 7 
post partum). Infants were followed from birth to 2 years of age. Of the sixty-two infants recruited, the parents of two declined to participate further after $1 \mathrm{~d}$ observations, one died aged 3 months and four moved out of the study area before they were fully weaned (at 2 , 7,12 and 17 months of age respectively). Data on initiation of supplementary feeding is, therefore, available for sixty infants, and data on duration of breast-feeding for fifty-five infants.

All infants in the study were born in hospitals or clinics; the incidence of home births in the general population (determined from the study's database) was $1.8 \%$. After delivery, the infant was usually taken to the nursery for a period of time depending on hospital routine and the condition of the mother. Once released from the nursery, mother and infant roomed in, sharing the same bed until discharged from hospital. Of the mothers, $38 \%$ initiated breast-feeding within $24 \mathrm{~h}$, and by $3 \mathrm{~d}$ post partum $90 \%$ of mothers were breastfeeding. Colostrum was fed by $72 \%$ of mothers. Of the infants, $66 \%$ received prelacteal feeds of water $(38 \%)$ or infant formula $(28 \%)$, while $7 \%$ were not fed anything before their first breast-feed. In $27 \%$ of cases, mothers did not know whether prelacteal feeds had been given by hospital staff.

At the first study visit on day 15 post partum, the mother was asked whether she had given her infant supplements yet (excluding the period in hospital when infant feeding was under the control of hospital staff), and if so, the infant's age and the type of supplement. Supplements were defined as anything other than breast-milk and water. The question was repeated at subsequent study visits by project staff at 45, 90, 180,270 and $360 \mathrm{~d}$ of age until the infant had received the first supplementary foods. Breast-feeding duration was determined by asking the mother at each study visit in year 1 and at bimonthly visits in year 2 whether she was still breast-feeding, and if not, the age at which the infant was fully weaned (no longer sucked at the breast) and why the mother had decided to stop breastfeeding at that time.

To quantify the amount of supplementary food received, the infant's intake of supplements and breast-milk was measured directly during $48 \mathrm{~h}$ continuous study at each of the six visits in the first year of life, and energy, nitrogen and protein intakes analysed as described by Jackson et al. $(1988,1990)$. Infant birth weights were obtained from hospital or health-centre records.

Data relating to wealth (type and size of housing, sanitation, number of selected consumer goods owned, land holdings, cash-flow equivalent), occupation, education, household structure, parental age and maternal reproductive history (including contraceptive use) were obtained by questionnaire administered by the field staff. To obtain a composite measure of wealth, relevant variables were reduced by means of principle components analysis (SPSS/PC + Factor Analysis (Norusis, 1988)) to three orthogonal factors, explaining $61 \%$ of their variance. The first factor loaded on house size, housing quality, possession of latrine, extended family, land ownership and consumer goods owned and was, thus, a measure of material wealth typical of well-to-do rural households. The second factor loaded on father not employed in agriculture, mother not employed in agriculture and residence in the least remote part of the study area and was, thus, a measure of urbanization. The third factor loaded on maternal and paternal education and income (cash flow). Factor scores for the first component and cash income were used as two separate measures of household wealth.

\section{RESULTS}

\section{Supplementary feeding patterns}

Of the infants, $13 \%$ received their first supplements within $7 \mathrm{~d}$ after birth; $81 \%$ of infants had been given supplementary foods by 6 weeks of age. Median age of introduction of 


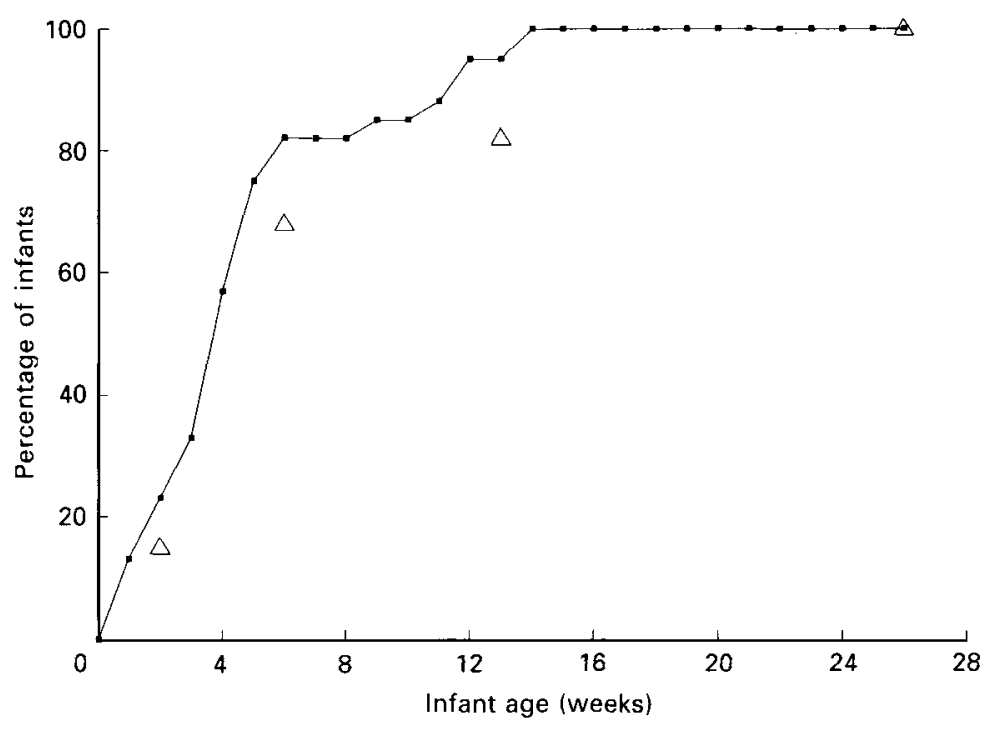

Fig. 2. Age (weeks) at which supplements were first introduced among infants in northern Thailand. $\triangle$ Percentage of infants observed taking supplements at study visits.

Table 1. Type of first supplementary food received by infants in northern Thailand and age of infant at time of introduction

(Values are given as percentage of infants $(n 60)$ )

\begin{tabular}{|c|c|c|c|c|c|}
\hline \multirow[b]{2}{*}{ First supplementary food } & \multicolumn{4}{|c|}{ Infant age (weeks) } & \multirow{2}{*}{$\begin{array}{c}\text { Total percentage } \\
\text { of infants }\end{array}$} \\
\hline & $1-2$ & $3-6$ & $7-13$ & $14-26$ & \\
\hline Premasticated rice & 13 & 20 & 2 & - & 35 \\
\hline Mashed or pounded rice & 3 & 20 & 5 & 5 & 33 \\
\hline Infant formula & 7 & 7 & - & - & 14 \\
\hline Orange juice & - & 7 & 3 & - & 10 \\
\hline Commercial cereal & - & 3 & 2 & - & 5 \\
\hline Banana & - & 2 & 2 & - & 4 \\
\hline
\end{tabular}

supplementary foods was 4 weeks (Fig. 2). Points on Fig. 2 indicate supplementary feeding observed directly at each of the study visits. The apparent discrepancy is because $18 \%$ of mothers did not immediately continue feeding supplements after introducing them for the first time.

In most cases, rice-based foods were the first supplements offered (Table 1). These were softened to a semi-solid consistency by pounding or mastication, and the rice-and-saliva mixture left to stand for a short while before feeding to the infant. In rural northern Thailand, glutinous rice (Oryza glutinosa) is preferred to ordinary rice (Oryza sativa). It is prepared by steaming after soaking overnight. Glutinous rice absorbs less water than ordinary rice and has more grains per unit volume (MacLean et al. 1978), contributing to the relatively high energy density of rice dishes (Appendix 1).

Altogether 211 different supplementary foods or food preparations were recorded over the first year of life. Fig. 3 illustrates how frequencies of the eight most common food 

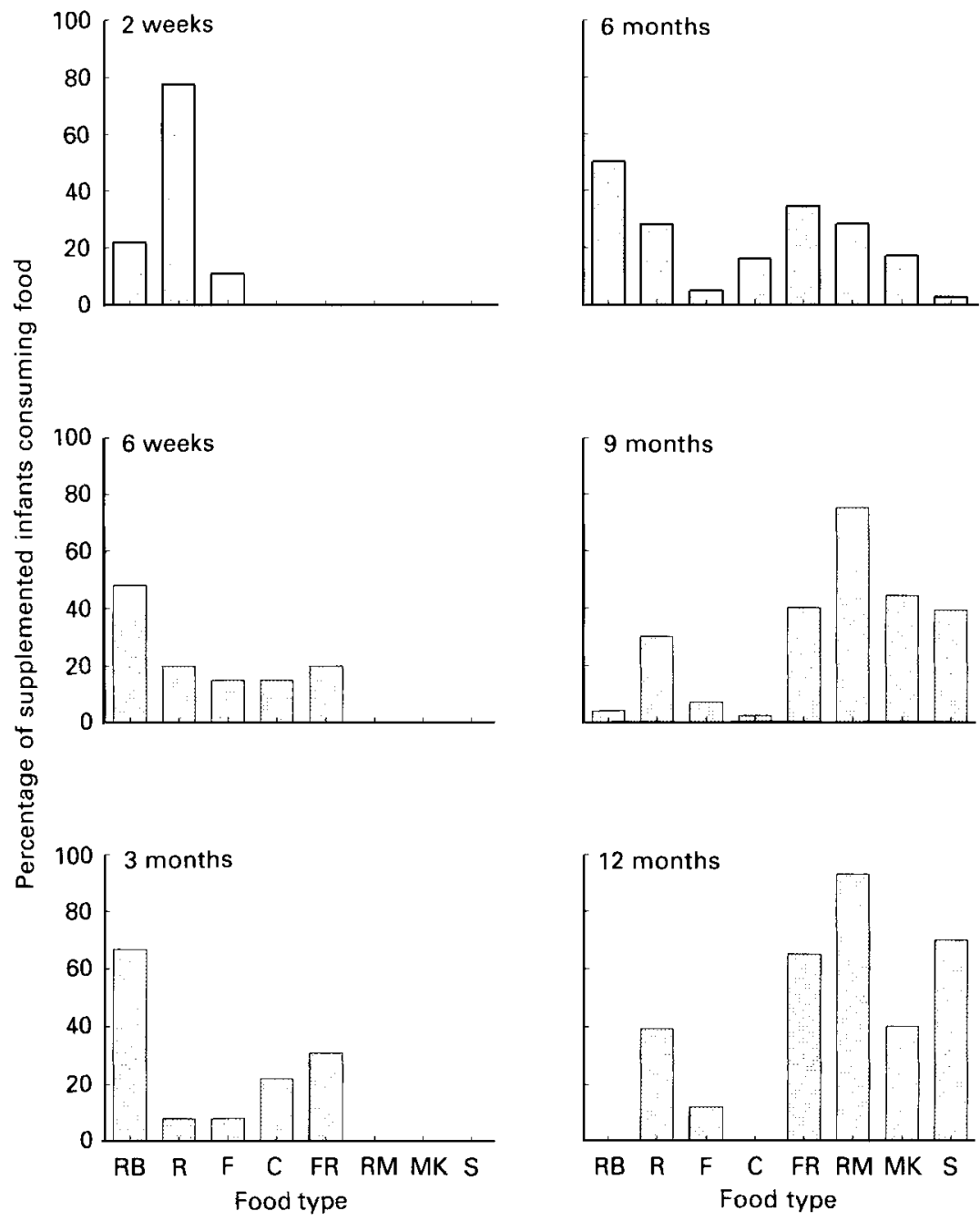

Fig. 3. Percentage of supplemented northern Thai infants consuming eight common food preparations: RB, rice and banana; $R$, rice alone; $F$, commercial infant formula ; $C$, commercial infant cereal; $F R$, fruit or fruit juice ; $\mathrm{RM}$, rice and meat; $\mathrm{MK}$, meat khawtom; S, snacks.

preparations changed with increasing infant age. Fig. 4 shows changing frequency of the main ingredients of meals. The composition of the main food preparations is given in Appendix 1. From 2 to 6 weeks the supplementary diet consisted predominantly of mashed rice and banana, or rice alone. Infant-formula, commercial infant cereal and fresh fruit juice were also given. Mashed rice and banana remained the most common supplementary food at 3 months of age, followed by fresh fruit and fruit juice and commercial infant cereal. By 6 months of age all infants in the study were supplemented. Mashed rice and banana was still widely given, but a major new component of the supplementary diet consisted of meat (pork, fried pork-skin, liver, fish or egg) prepared as soft meat and rice mixtures or meat 'khawtom' (a soft rice soup, similar to congee). Altogether, $45 \%$ of infants received meat in some form in their diet at 6 months of age (Fig. 4). Fresh fruit was also commonly given. 


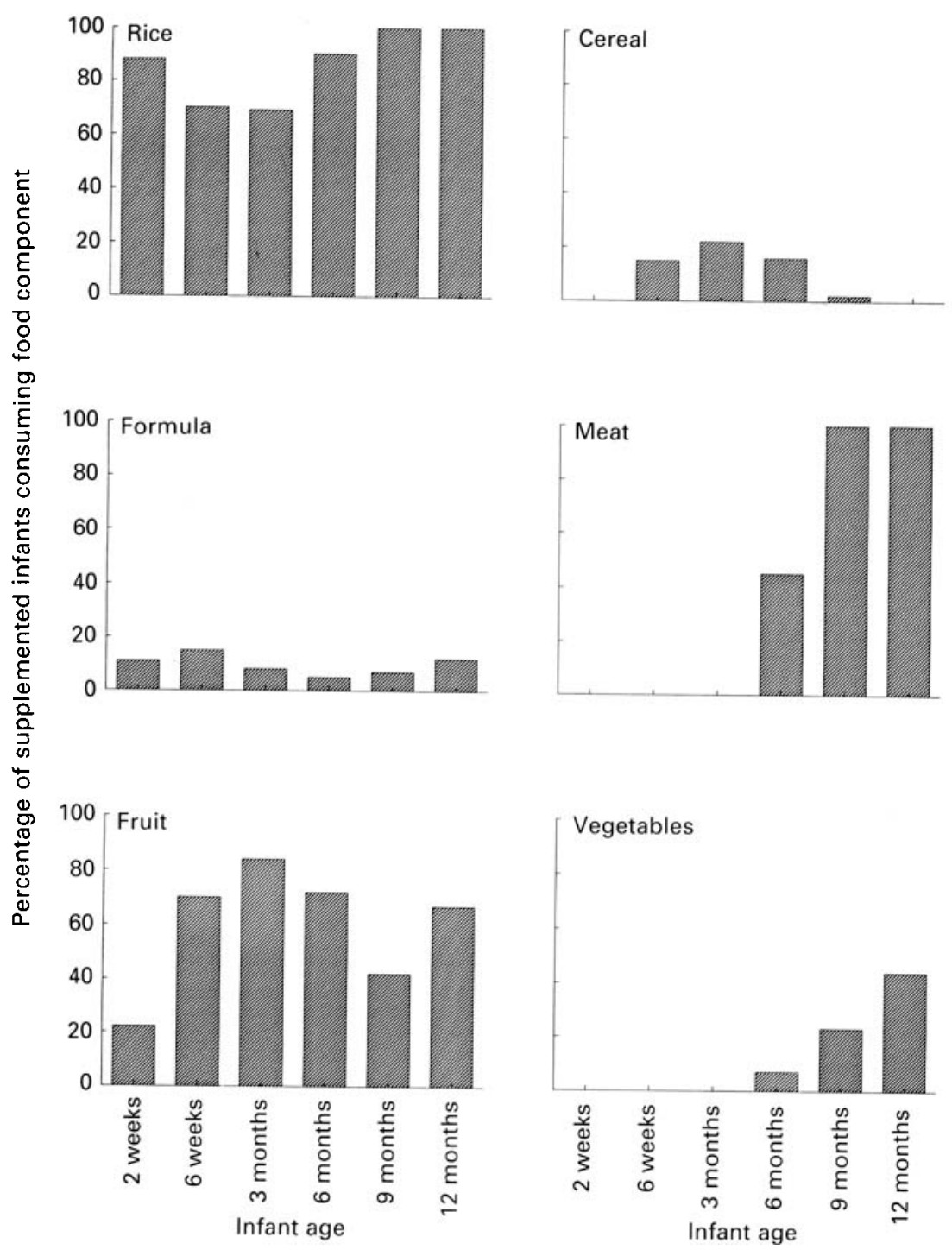

Fig. 4. Percentage of supplemented northern Thai infants consuming six main components of the diet.

At 9 and 12 months of age, rice and banana was phased out of the diet with increasing consumption of meat-containing dishes. These tended to be of more solid consistency, often fed as lumps of rice alternating with premasticated pieces of meat, although semi-solid meat khawtoms continued to be given. Snacks (Thai: 'khanom') formed a heterogenous collection including rice-based dishes with coconut milk or agar-agar jelly, or both, wheat products such as bread, cake, biscuits and dumplings, prawn crackers, soya-bean milk and tapioca. Snacks were more frequently given at 9 and 12 months of age. Premasticated foods were given throughout the first year of life (Fig. 5). 


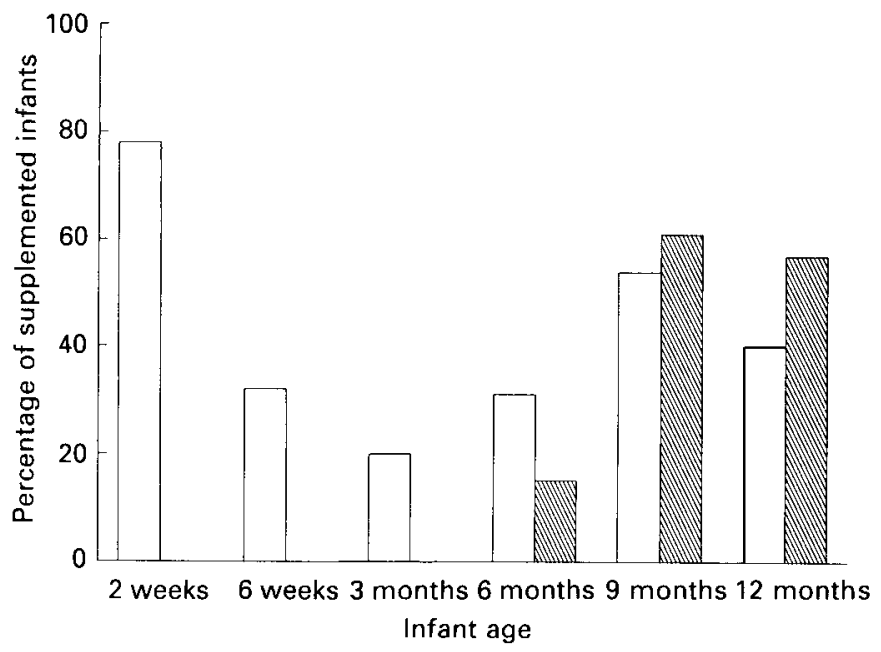

Fig. 5. Percentage of supplemented northern Thai infants consuming premasticated rice-based foods ( $\square)$ and meat $(\mathbb{Q})$.

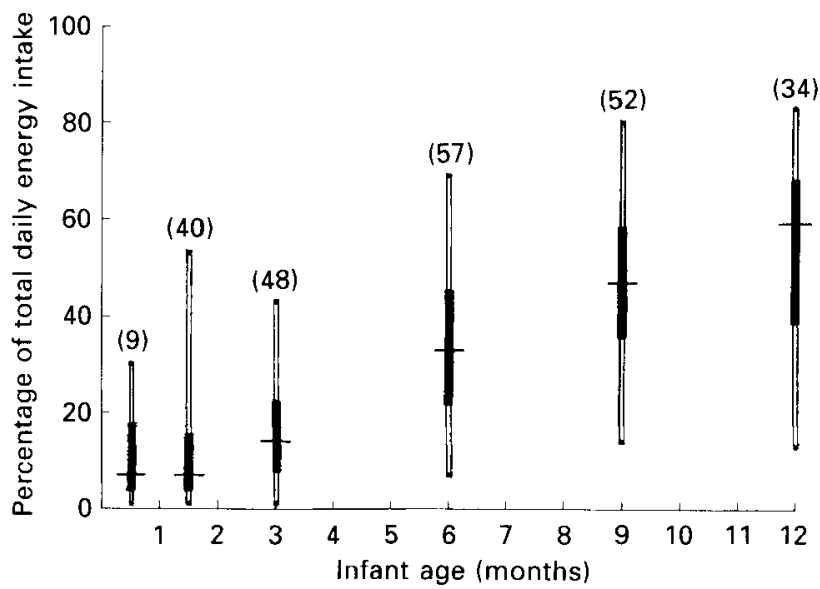

Fig. 6. Percentage of daily energy intake obtained from supplementary foods by partially breast-fed northern Thai infants (median, upper and lower quartiles and range). Number of infants shown in parentheses.

The amount of supplementary food given in the early months was relatively small, but not negligible. Up to 3 months of age, supplements contributed median values of $7-14 \%$ of the total daily energy intakes in those infants who were supplemented (Fig. 6). The percentage of infants receiving more than one-quarter of their daily energy intake from supplements was 11,8 and $21 \%$ at 2 weeks, 6 weeks and 3 months of age respectively. By 6 months of age supplementary foods contributed median values of $33 \%$, and at 9 and 12 months of age, 47 and $59 \%$ of the daily energy intake in infants who were still partially breast-fed (Fig. 6). 


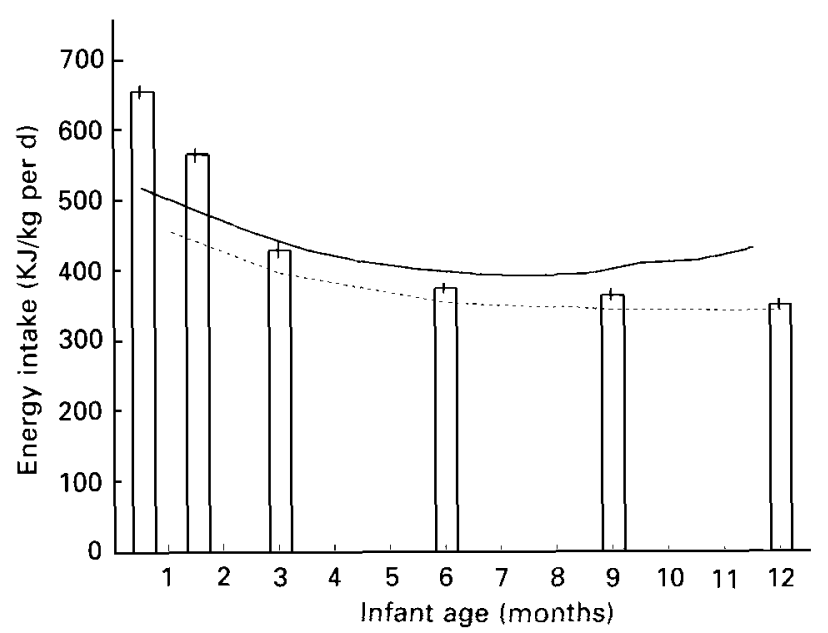

Fig. 7. Energy intakes ( $\mathrm{KJ} / \mathrm{kg}$ body-weight per $\mathrm{d}$ ) of northern Thai infants compared with the Food and Agriculture Organization/World Health Organization/United Nations University (1985) recommended daily intakes ( - ) and revised values proposed by Prentice et al. (1988) (--). Values are means with their standard errors represented by vertical bars.

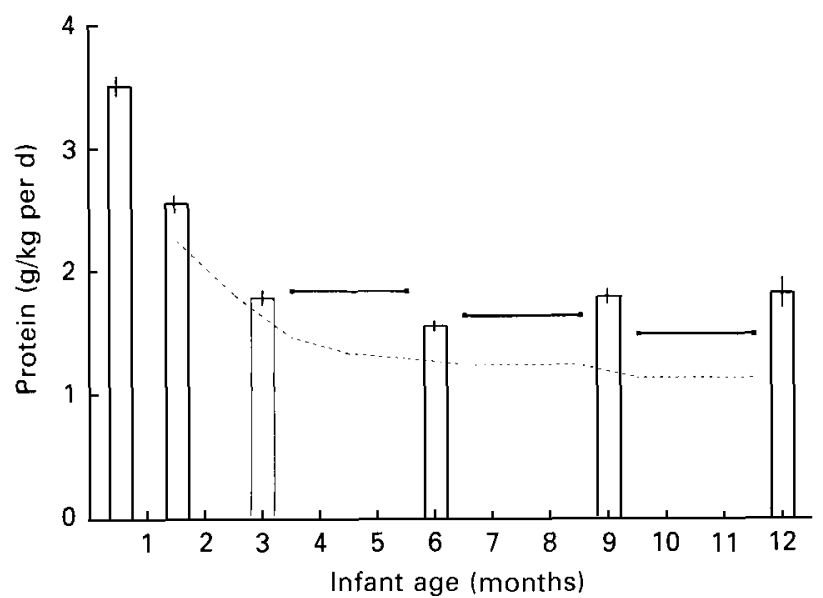

Fig. 8. Protein intakes (g/kg body-weight per d) of northern Thai infants compared with 'safe ' ( (--) daily intakes recommended by the Food and Agriculture Organization/World Health Organization/United Nations University (1985). The 'safe' level of intake incorporates an allowance for catch-up growth. Values are means with their standard errors represented by vertical bars.

Figs. 7 and 8 show the total dietary and protein intakes (corrected for biological availability as recommended by the Food and Agriculture Organization/World Health Organization/United Nations University (1985) (Jackson et al. 1988)) per kg body-weight over the first year of life. Energy intakes exceeded the guidelines for healthy children in affluent societies proposed by Prentice et al. (1988), and supported by Dewey et al. (1989). However, in comparison with the recommended daily intakes published by the Food and Agriculture Organization/World Health Organization/United Nations University (1985), energy intakes were 10-20\% less than recommended for infants aged 6-12 months. Protein intakes were comparable with or exceeded recommended daily intakes. 
Table 2. Predictors of infant age when supplementary foods first given in northern Thailand

(Dependent variable: age of first introduction of supplementary foods (weeks) $\left(\log _{10}\right)$ )

\begin{tabular}{|c|c|c|c|c|c|}
\hline Predictor variables & $B$ & $\beta$ & $\begin{array}{c}\text { Statistical } \\
\text { significance* } \\
P\end{array}$ & Overall $R^{2}$ & \\
\hline Household size $\left(\log _{10}\right)$ & -0.867 & $-0 \cdot 343$ & 0.005 & - & \\
\hline $\begin{array}{l}\text { Residence ( } 1 \text {, most remote area; } \\
2 \text {, intermediate } ; 3 \text {, least remote area) }\end{array}$ & 0.097 & 0.261 & $0 \cdot 030$ & - & \\
\hline $\begin{array}{l}\text { Mother's employment ( } 1 \text { farmer, } \\
0 \text { other) }\end{array}$ & -0.196 & $-0 \cdot 312$ & $0 \cdot 012$ & - & \\
\hline Mother's age & $-0 \cdot 015$ & $-0 \cdot 224$ & $0 \cdot 055$ & - & \\
\hline Sex of infant ( 0 boy, 1 girl) & $-0 \cdot 140$ & -0.223 & $0 \cdot 060$ & 一 & \\
\hline Birth wt (SD score) & 0.079 & $0 \cdot 213$ & $0 \cdot 070$ & - & \\
\hline Constant & $1 \cdot 393$ & - & - & 0.352 & $P<0.001$ \\
\hline
\end{tabular}

$B$, Regression coefficient; $\beta$, standardized regression coefficient; so score, standard deviation score.

* Significance values for each variable are as if entered last into the model, i.e. adjusted for all other variables in the model.

Timing of first supplementary feeds

Variables associated with the age when the infant first received supplementary food were analysed using hierarchical multiple linear regression. Predictor variables examined included: maternal and paternal employment, maternal education, household size, subdistrict in which the family was resident, maternal age, infant's birth weight (standard deviation from National Centre for Health Statistics median (World Health Organization, 1983), infant's sex, cash income and a score of household wealth obtained from principle components analysis (see p. 151). Variables were corrected for skewness using log transformation where appropriate. Predictor variables with bivariate correlation exceeding $r 0.25$ ( $P$ approximately 0.05 ) with the outcome variable were entered first into the multipleregression model. The remaining variables were then examined for significance, and entered if appropriate. Final residuals were examined for normality.

The initial regression analysis showed that supplementary foods were introduced significantly earlier if the infant was born into a large household $(P=0.018)$, or one residing in the more remote part of the study area $(P=0.019)$, or if the mother's main occupation was farming (either on the household's own land, as a wage labourer or share cropper) $(P=0.030)$. In addition, there was a tendency for older mothers to supplement earlier $(P=0.076)$. These four variables explained $28 \%$ of the variance in the dependent variable. With these four variables in the model, girls and infants with lower birth weights tended to be supplemented earlier ( $P=0.06$ and $P=0.07$ respectively), and these two variables were therefore included in the model, increasing the significance of household size, mother's occupation and mother's age. The final model explained $35 \%$ of the variance in age of first supplementary feeding (Table 2).

\section{Duration of breast-feeding}

By the end of their first year, thirty-four of the fifty-seven infants were still breast-fed $(60 \%)$. Four infants $(7 \%)$ were still breast-feeding at 24 months of age. The majority of infants $(63 \%)$ were completely weaned between 10 and 15 months of age (Fig. 9). The median age of complete weaning was 12 months, ranging from 1 month to 23 months of age. 


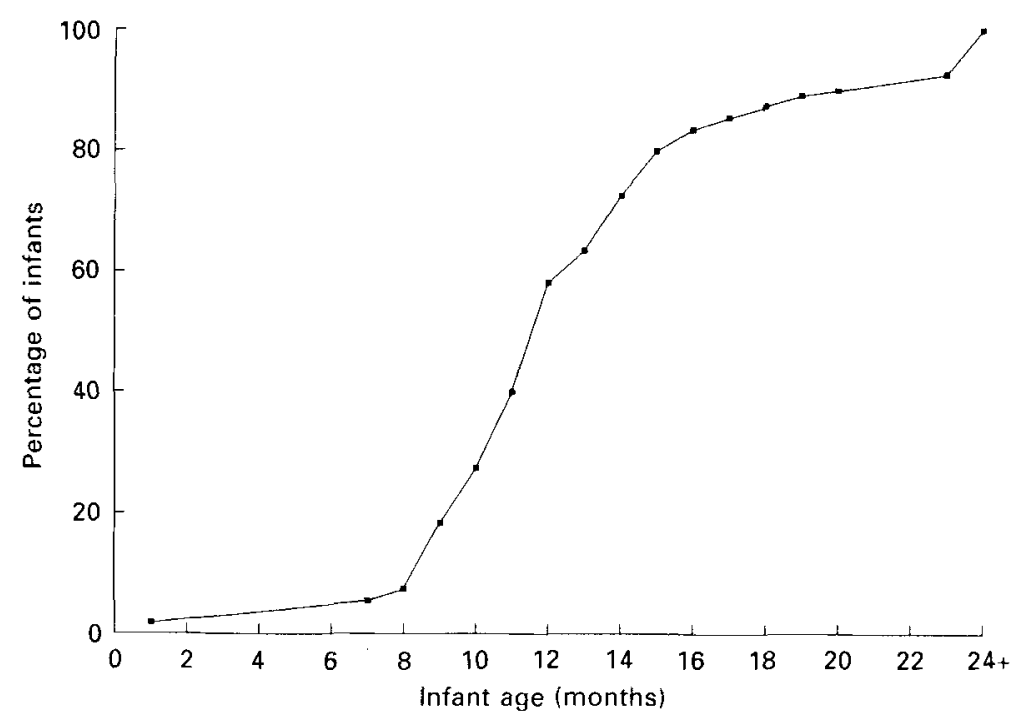

Fig. 9. Age (months) at which northern Thai infants were completely weaned from the breast.

Table 3. Reasons given for stopping breast-feeding among mothers in northern Thailand Diagonal shows percentage of mothers quoting a single reason for stopping, off-diagonals are percentage of mothers giving two reasons)

\begin{tabular}{lcccc}
\hline \hline Second reason & Time to stop & $\begin{array}{c}\text { Problem with } \\
\text { breast-feeding }\end{array}$ & $\begin{array}{c}\text { Mother returning } \\
\text { to work }\end{array}$ & Other \\
\hline Time to stop & 37 & 8 & 10 & 4 \\
Problem with breast-feeding & - & 18 & 0 & 0 \\
Mother returning to work & - & - & - & 10 \\
Other & - & - & - & 11 \\
\hline \hline
\end{tabular}

The most common single reason mothers gave for complete weaning was 'it was time to stop' or 'baby old enough' ( $37 \%$ of mothers, Table 3 ) as indicated by signs such as the baby chewing on the nipple or the baby growing well. A further $22 \%$ of mothers gave this reason in conjunction with: the mother's return to work (10\% of cases), problems of breast-feeding $(8 \%)$ and 'other' reasons $(4 \%)$. Altogether, $26 \%$ of mothers reported cessation of breast-feeding associated with problems such as insufficient milk or fall-off in milk production, painful feeding, cracked nipples or 'watery breast- milk'. Over all, $22 \%$ of mothers cited their return to work as a reason for stopping breast-feeding. Other reasons $(17 \%)$ included the belief that it would be more difficult to wean an older infant, greater convenience of giving supplementary foods, or the recommendations of relatives.

There were no significant differences in reasons for stopping breast-feeding between mothers who stopped before 12 months and those who stopped after 12 months, except that mothers who stopped earlier were more likely to do so for 'other' reasons $(32 \% \mathrm{v.7} \%$, $P<0 \cdot 05)$. 
Table 4. Factors associated with duration of breast-feeding among mothers in northern Thailand

(Dependent variable: duration of breast-feeding (months) $\left(\log _{10}\right)$ )

\begin{tabular}{|c|c|c|c|c|c|}
\hline Predictor variables & $B$ & $\beta$ & $\begin{array}{c}\text { Statistical } \\
\text { significance* } \\
P\end{array}$ & Overall $R^{2}$ & \\
\hline Mother's age & $0 \cdot 010$ & 0.357 & $0 \cdot 023$ & - & \\
\hline No. of children in household & $-0 \cdot 072$ & -0.298 & 0.049 & - & \\
\hline $\begin{array}{l}\text { First supplementary food was } \\
\text { infant formula }\end{array}$ & $-0 \cdot 117$ & -0.330 & $0 \cdot 036$ & - & \\
\hline Constant & $0 \cdot 96$ & - & - & $0 \cdot 145$ & $P=0.048$ \\
\hline
\end{tabular}

$B$, Regression coefficient; $\beta$, standardized regression coefficient.

* Significance values for each variable are as if entered last into the model, i.e. adjusted for all other variables in the model.

\section{Factors predicting duration of breast-feeding}

Early consumption of supplementary foods could contribute to early cessation of breastfeeding due to reduced suck ling leading to reduced breast-milk synthesis. This question was explored by hierarchical multiple-regression analysis. The predictor variables under test were: the age at which supplementary foods were introduced, whether infant formula was the first supplement given, and the average daily energy intake from supplements in the first 3 months. The latter variable was calculated from the measured supplementary energy intakes at $15 \mathrm{~d}, 45 \mathrm{~d}$ and $90 \mathrm{~d}$ weighted by the time interval between measurements, and expressed in absolute terms and as a percentage of total energy intake. One infant was completely weaned by 1 month of age. His subsequent energy intake from supplements could not, therefore, have affected breast-feeding duration, and so this case was excluded from the analysis. Control independent variables were: sex of the infant, age and educational level of mother, parity, number of children in the household, household size, hormonal contraceptive use, maternal and paternal employment in agriculture, sub-district in which the family was resident, cash income, and a score of material wealth (see p. 151). For the four infants who were still breast-feeding at 24 months of age, duration of breastfeeding was set to 24 months. Variables were corrected for skewness by logarithmic transformation where appropriate, and final residuals were inspected for normality.

Infants were breast-fed for a shorter period of time if the mother was younger, if there were more children in the household and if infant formula was given as the first supplementary food (Table 4). Early introduction of supplements per se was not a significant predictor of duration of breast-feeding, and giving larger quantities of supplementary foods in the first 3 months did not predispose to earlier cessation of breastfeeding. The latter two variables were not statistically significant at any stage in the analysis: $t$ value to enter $-1.178(P=0.244)$ and $0.854(P=0.397)$ respectively; $t$ value to enter last $-1.657(P=0 \cdot 104)$ and $0.579(P=0.562)$ respectively.

\section{DISCUSSION}

The supplementary diet of breast-fed infants in the Sanpatong district of northern Thailand is based on glutinous rice as the staple carbohydrate source. Rice-based supplements were introduced in the first days or weeks after birth. Fruit or fruit juice was given from 2 weeks of age. Meat, fish or eggs, and purchased snacks, were not given until after 6 months of age. 
Vegetables were rarely given in the first year of life, except small quantities in soups. Rice and meat were often softened by premastication before feeding. Commercial infant formula and cereal were used by a minority of mothers.

The timing of supplementary feeding and types of foods described here comprise a pattern of infant feeding which is widespread through central South-east Asia, including Burma (Tin Tin Oo \& Khin Maung Naing, 1985), Vietnam (Nguyen Tha Nga \& Weissner, 1986) and the rural peoples of northwest and northeast Thailand and Laos (Bisolyaputra \& Bocobo, 1957; Valyasevi et al. 1967; Sriboonlue et al. 1983; Valyasevi, 1988). These peoples share common ethnic origins reflected in linguistic and cultural similarities (Wongthes \& Wongthes, 1989).

The nutritional quality of the supplementary diet was high, providing a wide variety of foods in the second half of the first year of life. All infants received protein of animal origin (meat, fish or egg) from the age of 9 months onwards. For comparison, in a study in Bangladesh only $5 \%$ of infants aged 12 months had ever received meat, fish or egg (Brown et al. 1982). Nutrient values of supplementary foods (Appendix 1) were comparable with or exceeded those reported from other studies (Jackson et al. 1988). Protein intakes met or exceeded the recommended daily intakes. Energy intakes were higher than the most recent proposed guidelines, but in infants aged 6-12 months intakes were 10-20\% less than recommended daily intakes adopted by the Food and Agriculture Organization/World Health Organization/United Nations University (1985).

The extent of early supplementary feeding in developing countries has not been systematically monitored (Notzon, 1984), but available data suggest that the practice is widespread except on the Indian subcontinent (Khan, 1980; World Health Organization, 1981; Brown et al. 1982). In Ethiopia, Nigeria, Zaire and the Philippines, roughly one-third of rural infants were reported to be receiving regular supplements by the age of 2-3 months, with a higher rate in Chile ( $56 \%$ of infants; World Health Organization, 1981). A study of infant feeding practice in Malaysia, Kenya and Mexico concluded that, over all, only $11 \%$ of infants under 4 months of age were exclusively breast-fed (Dimond \& Ashworth, 1987). In Peru, $12 \%$ of infants were exclusively breast-fed at 1 month of age (Brown et al. 1989) and in East Java, 22\% (Kusin et al. 1985).

Few studies have investigated the factors predisposing to early supplementation, especially the introduction of solid foods, and the effect on breast-feeding duration, controlling for covariates (Forman, 1984). In the sample studied here, early supplementary feeding (mainly semi-solid rice preparations) occurred in large households residing in the remoter part of the study area and earning their living through farming. Older mothers also supplemented earlier. Early supplementation was, thus, associated with features of the traditional northern Thai way-of-life. Conversely, mothers living in the more urbanized part of the study area, in nuclear families and employed in non-agricultural jobs were more likely to supplement later. The precise sociological factors influencing mothers to depart from traditional practice are not clear. For instance, household wealth and maternal education were not associated with timing of supplementation; nevertheless, mothers adopting a more 'westernized' lifestyle may be exposed to health messages outside the education system.

In the Thai families studied here, despite early introduction of supplementary foods, breast-feeding duration was prolonged with a median duration of 12 months. Of the infants $7 \%$ were still breast-feeding at 24 months of age. Other studies also indicate that early supplementary feeding does not always lead to early cessation of breast-feeding (World Health Organization, 1981; Latham et al. 1986; Dimond \& Ashworth, 1987). This is not necessarily because the quantities of supplements given are small: an early study in northeast Thailand showed that even where rice supplements provided about half the 
total energy requirements of 30 -d-old infants, modal breast-feeding duration was over 24 months (Valyasevi et al. 1967).

Only $15 \%$ of the variance in duration of breast-feeding amongst mothers in Sanpatong was explained by the multiple-regression model. Early supplementation per se was not associated with shorter duration of breast-feeding. However, the distinction between infant formula and traditional semi-solid rice supplements appears to be important, since the eight mothers offering infant formula as the first supplementary food had a slightly shorter duration of lactation than those offering rice-based foods (median duration 10.5 months compared with 12 months, and Table 4). Mothers intending to breast-feed for a shorter period, or less enthusiastic about breast-feeding, may have deliberately started their infants on infant formula. Alternatively, formula given by bottle and teat may have competed against breast-feeding more effectively than foods fed by spoon or hand. Breast-feeding ceased earlier in households with more children, possibly reflecting demands on the mother's time or the availability of older siblings to help with supplementary feeding.

The reasons underlying the particular patterns of breast- and supplementary feeding observed in different communities are poorly understood. An association between early bottle feeding and early cessation of breast-feeding has been reported in many studies, usually linked to maternal reports of insufficient breast-milk (Forman, 1984), but there are also communities in which extensive bottle-feeding coexists with long breast-feeding duration (Franklin et al. 1983; Latham et al. 1986). Cultural perceptions (Van Esterik, 1985 a), social constraints (Gussler \& Briesemeister, 1980) and psychological factors (Sjolin et al. 1977) may explain these two contrasting feeding modes, but biological processes may also be important. In Sanpatong district it is customary for night-time breast-feeding to continue until the infant is completely weaned (Imong et al. 1989). By exploiting the higher levels of prolactin secretion at night (Bunner et al. 1978), this practice may increase mothers' physiological ability to maintain breast-milk production despite early supplementation.

Advice on infant feeding to mothers in developing countries has focused on promoting exclusive breast-feeding for the first few months of life, for nutritional reasons and also as a birth-spacing mechanism (Labbock \& Krasovec, 1990). One problem with this approach is the difficulty in identifying, both at the individual and at the population level, the point at which breast-milk alone will no longer meet infants' nutritional needs (Rowland, 1986). The educational message is weakened because it has to be phrased in terms of guidelines rather than a definitive instruction, and may be qualified by cautions such as 'a mother should follow her instincts and not be unnecessarily influenced by the opinions of experts' (Whitehead, 1985). Alternatively, health-programme personnel are supposed to evaluate maternal lactation and infant growth to advise the mother when she may start giving supplements (breast-feeding booklet of the International Institute for Studies in Natural Family Planning, 1990). The disparity between current recommendations as to when supplementary foods should be introduced and actual infant feeding practices in developing countries suggests that the traditional timing of supplementary feeding could be relatively resistant to change, and that mothers may more readily accept advice on what kind of food to give rather than when to give it (Ashworth \& Feachem, 1985).

Given the diversity of infant feeding practices amongst developing countries, breastfeeding advice could be made more effective by addressing local customs and constraints, rather than viewing developing countries as a homogeneous group. The present study and others cited previously have shown that long duration of breast-feeding and early supplementation are not necessarily incompatible. In such cases, public-health programmes which emphasize continued maintenance of breast-feeding (such as encouraging night-time breast-feeding) in conjunction with hygienic preparation and storage of supplementary foods may be more successful in promoting infant health than trying to eliminate early 
supplementation altogether. Such a policy would respect cultural reasons for early supplementation (for example, feeding rice to socialize the infant as a member of society (Van Esterik, 1985b)), and practical constraints such as maternal work commitments outside the home. In addition, improved hygiene in food preparation would benefit other family members, especially young children who are no longer breast-feeding.

This study is part of the Thai-UK collaborative Chiang Mai Lactation Project, supported by the Royal Thai Government and the International Development Research Centre, Canada. Additional funding was received from the Thrasher Research Fund (D. A. J.), the Overseas Development Administration, UK, and Ford Foundation (S.M.I.) and the University of Durham (R.F.D.),

\section{REFERENCES}

Ashworth, A. \& Feachem, R. G. (1985). Interventions for the control of diarrhoeal diseases among young children: weaning education. Bulletin of the World Health Organization 63, 1115-1127.

Bisolyaputra, U. \& Bocobo, D. L. (1957). Dietary surveys in four areas of Thailand. Journal of the Pharmacological Association of Thailand 10, 175-204.

Brown, K. H., Black, R. E., Becker, S., Nahar, S. \& Sawyer, J. (1982). Consumption of foods and nutrients by weanlings in rural Bangladesh. American Journal of Clinical Nutrition 36, 878-889.

Brown, K. H., Black, R. E., Lopez de Romana, G. \& Creed de Kanashiro, H. (1989). Infant-feeding practices and their relationship with diarrheal and other diseases in Huascar (Lima), Peru. Pediatrics 83, 31-40.

Bunner, D. L., VanderLaan, E. F. \& VanderLaan, W. P. (1978). Prolactin levels in nursing mothers. American Journal of Obstetrics and Gynecology 131, 250-252.

Dewey, K. G., Heinig, M. J., Nommsen, L. A. \& Lonnerdal, B. (1989). Dietary guidelines for infants. Lancet $\mathbf{i}$ 504 .

Dimond, H. J. \& Ashworth, A. (1987). Infant feeding practices in Kenya, Mexico and Malaysia. Human Nutrition: Applied Nutrition 41 A, 51-64.

Food and Agriculture Organization/World Health Organization/United Nations University (1985). Energy and protein requirements. Report of a Joint FAO/WHO/UNU Expert Consultation. Technical Report Series, no. 724. Geneva: WHO.

Forman, M. R. (1984). Review of research on the factors associated with choice and duration of infant feeding in less-developed countries. Pediatrics 74, Suppl., 667-694.

Franklin, R. R., Bertrand, W. E., Mock, N. B., Nkamany, K. \& McCaw, A. (1983). Feeding patterns of infants and young children in Kinshasa, Zaire. Journal of Tropical Pediatrics 29, 255-259.

Gussler, J. D. \& Briesemeister, L. H. (1980). The insufficient milk syndrome: a biocultural explanation. Medical Anthropology 4, 1-24.

Imong, S. M., Jackson, D. A., Wongsawasdii, L., Ruckphaopunt, S., Tansuhaj, A., Chiowanich, P., Woolridge, M. W., Drewett, R. F., Baum, J. D. \& Amatayakul, K. (1989). The predictors of breastmilk intake in rural northern Thailand. Journal of Pediatric Gastroenterology and Nutrition 8, 359-370.

Imong, S. M., Jackson, D. A., Wongsawasdii, L., Ruckphaopunt, S., Woolridge, M. W., Amatayakul, K. \& Baum, J. D. (1988). Indirect Test Weighing: a new method for measuring overnight breastmilk intakes in the field. Journal of Pediatric Gastroenterology and Nutrition 7, 699-706.

International Institute for Studies in Natural Family Planning (1990). Breastfeeding; Protecting a Natural Resource. Georgetown University, USA: International Institute for Studies in Natural Family Planning, Georgetown University.

Jackson, D. A., Imong, S. M., Silprasert, A., Wongsawasdii, L., Chiowanich, P., Ruckphaopunt, S., Williams, A. F., Woolridge, W. M., Drewett, R. F., Amatayakul, K. \& Baum, J. D. (1988). Infant weight in relation to nutritional intake and morbidity in northern Thailand. European Journal of Clinical Nutrition 42, 725-739.

Jackson, D. A., Imong, S. M., Woolridge, M. W., Wongsawasdii, L., Chiowanich, P., Drewett, R. F., Baum, J. D. \& Amatayakul, K. (1990). Supplementary feeding and infant growth in northern Thailand. In Breastfeeding, Nutrition, Infection and Infant Growth in Developed and Emerging Countries, pp. 282-287 [S. A. Atkinson, L. A Hanson and T. K. Chandra, editors]. St John's, Newfoundland, Canada: ARTS Biomedical Publishers and Distributers.

Khan, M. (1980). Infant feeding practices in rural Meheran, Comilla, Bangladesh. American Journal of Clinical Nutrition 33, 2356-2364.

Kusin, J. A., Kardjati, S, \& van Steenbergen, W. (1985). Traditional infant feeding practices: right or wrong? Social Science and Medicine 21, 283286.

Labbock, M. H. \& Krasovec, K. (eds) (1990). In Guidelines for Breastfeeding in Child Survival and Family Planning Programmes. Georgetown University, USA: International Institute for Studies in Natural Family Planning, Georgetown University. 
Latham, M. C., Elliott, T. C., Winikof, B., Kekovole, J. \& Van Esterik, P. (1986). Infant feeding in urban Kenya: a pattern of early triple nipple feeding. Journal of Tropical Pediatrics 32, 276-280.

MacLean, W. C., Klein, G. L., Lopez de Romana, G., Massa, E. \& Graham, G. G. (1978). Protein quality of conventional and high protein rice and digestibility of glutinous and non-glutinous rice by preschool children. Journal of Nutrition 108, 1740-1747.

Nguyen Tha Nga \& Weissner, P. (1986). Breastfeeding and young child nutrition in Uong Bi, Quang Ninh Province, Vietnam. Journal of Tropical Pediatrics 32, 137-139.

Norusis, M. J. (1988). SPSS/PC+. Chicago: SPSS Inc.

Notzon, F, (1984). Trends in infant feeding in developing countries. Pediatrics 74, Suppl., 648-666.

Prentice, A. M., Lucas, A., Vasquez-Velasquez, L., Davies, P. S. \& Whitehead, R. G. (1988). Are current dietary guidelines for young children a prescription for overfeeding? Lancet ii, 10661069.

Rowland, M. G. M. (1986). The weanling's dilemma: are we making progress? Acta Paediatrica Scandinavica, 323, Suppl., 33-43.

Sjolin, S., Hofvander, Y. \& Hillervik, C. (1977). Factors related to early termination of breastfeeding. Acta Paediatricia Scandinavica 66, 505-511.

Sriboonlue, P., Prasongwatana, V., Prasongwatana, J., Mularee, N., Sanchaisuriya, P., Moonamerd, S. \& Saowakontha, S. (1983). Breastfeeding practices and food beliefs among the Pootai in northeast Thailand. Bulletin of the Khon Kaen University Health Sciences 9, 197-203.

Tin Tin Oo \& Khin Maung Naing (1985). Breast-feeding and weaning practices for infants and young children in Rangoon, Burma. Food and Nutrition Bulletin 7, 47-53.

Underwood, B. A. \& Hofvander, Y. (1982). Appropriate timing for complementary feeding of the breast-fed infant. A review. Acta Paediatrica Scandinavica 294, Suppl., 1-32.

Valyasevi, A. (1988). Nutritional problems during weaning period in Thai children. Hong Kong Journal of Paediatrics 1, Suppl., 88-94.

Valyasevi, A., Halstead, S., Pantuwatana, S. \& Tankayul, C. (1967). Studies of bladder-stone disease in Thailand. IV. Dietary habits, nutritional intake and infant feeding practices among residents of a hypo- and a hyperendemic area. American Journal of Clinical Nutrition 20, 1340-1351.

Van Esterik, P. (1985a). Commentary: an anthropological perspective on infant feeding in Oceania. In Infant Care and Feeding in the South Pacific, pp. 331-343 [L. B. Marshall, editor]. New York: Gordon \& Breach.

Van Esterik, P. (1985b). The cultural context of breastfeeding in rural Thailand. In Breastfeeding, Child Health and Child Spacing, pp. 139-161 [V. Hall and M. Simpson, editors]. London: Croom Helm.

Whitehead, R. G. (1985). Infant physiology, nutritional requirements and lactational adequacy. American Journal of Clinical Nutrition 41, 447-458.

Wongthes, P. \& Wongthes, S. (1989). Art, culture and environment of Thai-Lao-speaking groups. In Culture and Environment of Thailand: a Symposium of the Siam Society, pp. 161-169. Bangkok: Siam Society.

World Health Organization (1981). Contemporary Patterns of Breastfeeding. Geneva: WHO.

World Health Organization (1983), Measuring Change in Nutritional Status. Geneva: WHO. 
Appendix 1. Energy and crude protein* content of main types of supplementary foods (Mean values and standard deviations)

\begin{tabular}{|c|c|c|c|c|c|}
\hline \multirow[b]{2}{*}{ Food type } & \multicolumn{2}{|c|}{$\begin{array}{l}\text { Energy } \\
(\mathrm{kJ} / \mathrm{kg})\end{array}$} & \multicolumn{2}{|c|}{$\begin{array}{c}\text { Protein } \\
(\mathrm{g} / \mathrm{kg})\end{array}$} & \multirow{2}{*}{$\begin{array}{l}\text { No. of } \\
\text { samples }\end{array}$} \\
\hline & Mean & SD & Mean & SD & \\
\hline Rice and banana & 4430 & 1920 & 23 & 12 & 283 \\
\hline Mashed/premasticated rice & 8490 & 3590 & 35 & I1 & 229 \\
\hline Unmashed rice & 10700 & 2420 & 41 & 5 & 97 \\
\hline Rice and meat mixed in dish & 5680 & 2010 & 44 & 15 & 33 \\
\hline Rice and meat fed as alternate mouthfuls & 11540 & 2380 & 84 & 28 & 199 \\
\hline Rice and other food & 5680 & 3760 & 34 & 16 & 13 \\
\hline Infant formula & 2830 & 1050 & 20 & 12 & 126 \\
\hline Commercial cereal & 4260 & 1130 & 34 & 14 & 50 \\
\hline Cereal and banana & 5310 & 1590 & 41 & 20 & 28 \\
\hline Cereal and egg & 5180 & 1590 & 40 & 15 & 11 \\
\hline Orange & 1960 & 790 & 8 & 2 & 54 \\
\hline Orange juice & 1790 & 590 & 8 & 1 & 33 \\
\hline Banana & 5810 & 3220 & 15 & 8 & 45 \\
\hline Other fruit & 3470 & 2050 & 12 & 7 & 25 \\
\hline Pork & 14090 & 5020 & 288 & 83 & 132 \\
\hline Liver & 13670 & 3890 & 294 & 54 & 38 \\
\hline Fish & 13330 & 5100 & 270 & 104 & 47 \\
\hline Egg & 12000 & 4850 & 131 & 32 & 43 \\
\hline Fried porkskin & 26960 & 5100 & 280 & 121 & 51 \\
\hline Beef, chicken & 17100 & 6230 & 316 & 143 & 10 \\
\hline Meat and vegetable side dish & 5100 & 2090 & 56 & 13 & 9 \\
\hline Meat khawtom & 3640 & 1630 & 35 & 18 & 134 \\
\hline Khawtom without meat & 4680 & 2840 & 18 & 7 & 11 \\
\hline Meat/noodle soup & 4310 & 4770 & 49 & 19 & 10 \\
\hline Vegetables alone & 6560 & 6640 & 31 & 17 & 9 \\
\hline Wheat-based snack & 19060 & 4510 & 82 & 33 & 61 \\
\hline Rice-based snack & 14000 & 8070 & 61 & 61 & 36 \\
\hline Soya-bean milk & 2090 & 750 & 15 & 4 & 17 \\
\hline Cows' milk & 2470 & 1000 & 20 & 14 & 7 \\
\hline Breast-milk & 3220 & 250 & 11 & $2 \dagger$ & $60 \ddagger$ \\
\hline
\end{tabular}

* Nitrogen $\times 6 \cdot 25$, not adjusted for digestibility or amino acid balance.

+ True protein, determined spectrophotometrically.

$\ddagger$ Average breast-milk composition of sixty mothers. 